\title{
Determination of the crystal structure of CuSnTi by full profile Rietveld analysis
}

\author{
F. Weitzer \\ Institut für Physikalische Chemie, Universität Wien, Vienna, Austria \\ L. Perring ${ }^{\text {a) }}$ \\ Institut de Chimie Minérale et Analytique, Université de Lausanne, Switzerland \\ T. Shibayanagi and M. Naka \\ Joining and Welding Research Institute, Osaka University, Osaka, Japan \\ J. C. Schuster \\ Institut für Physikalische Chemie, Universität Wien, Vienna, Austria
}

(Received 27 September 1997; accepted 26 October 1999)

The crystal structure of the new ternary phase CuSnTi is determined by full profile Rietveld analysis of the powder diffractogram. 104 reflections were refined to a final $R_{\mathrm{Bragg}}$ value of $5.60 \%$. CuSnTi crystallizes with the spacegroup $P 6_{3} / m m c$ and is isostructural to $\mathrm{InNi}_{2}$. The lattice parameters are $a=0.439555(5) \mathrm{nm}$ and $c=0.601505(9) \mathrm{nm}$. (c) 2000 International Centre for Diffraction Data. [S0885-7156(90)00301-3]

\section{INTRODUCTION}

In the course of investigating phases occurring in $\mathrm{Cu}-$ Sn-Ti solder alloys (Uray et al., 1998) the structure of ternary phase $\mathrm{CuSn} \mathrm{Ti}_{5}$ was recently characterized (Schuster et al., 1999). This phase is a major constituent in $\mathrm{Cu}-\mathrm{Sn}-\mathrm{Ti}$ alloys having a wide range of compositions including alloys quite rich in $\mathrm{Cu}$ such as $\mathrm{Cu}_{45} \mathrm{Sn}_{25} \mathrm{Ti}_{30}$ (Naka et al., 1999). However, in the neighboring alloy $\mathrm{Cu}_{45} \mathrm{Sn}_{30} \mathrm{Ti}_{25}$ only traces of $\mathrm{CuSn}_{3} \mathrm{Ti}_{5}$ are observed and a new diffraction pattern occurs, which was not identifiable with any phase listed in the book of Villars and Calvert (1991). The present paper reports on the composition and crystal structure of this phase as determined by full profile analysis (Rietveld, 1969) of the $\mathrm{X}$-ray diffractogram.

\section{EXPERIMENT}

An alloy of composition $\mathrm{Cu}_{45} \mathrm{Sn}_{30} \mathrm{Ti}_{25}$ was arc melted from Ti sponge (purity: 99.8mass\%, from Sumitomo Sitix, Amagasaki, Japan), $\mathrm{Cu}$ and $\mathrm{Sn}$ ingots (purity: $99.9 \mathrm{mass} \%$, from Osaka Asahi, Osaka, Japan) sealed in evacuated quartz tubes, and heat treated at $800^{\circ} \mathrm{C}$ for $115 \mathrm{~h}$. No mass loss was observed during these steps. The alloy was pulverized manually in a tungsten carbide mortar and spread on a thin polymer foil. Powder photographs were taken in transmission using a Guinier-Huber chamber, $\mathrm{CuK} \alpha_{1}$-radiation, and $\mathrm{Ge}$ standard (pulverized from lump, metal purity $99.9999 \%$, from Johnson Matthey GmbH, Karlsruhe, Germany) assuming a lattice parameter of $a=0.5657906 \mathrm{~nm}$. The powder diffraction profile was recorded on a Philips PW 1051/81 diffractometer in the range of $2 \theta=5$ to $140^{\circ}$ in steps of $0.02^{\circ}$ using $\mathrm{Cu} K \alpha$-radiation $\left(\lambda K \alpha_{1}=0.154056 \mathrm{~nm}, \lambda K \alpha_{2}\right.$ $=0.154440 \mathrm{~nm}$ ). The width of the receiving slit was $0.1 \mathrm{~mm}$. Total measuring time was $48 \mathrm{~h}$, equivalent to $25.4 \mathrm{~s}$ per scan step.

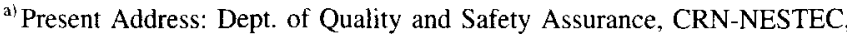
Lausanne, Switzerland.

\section{REFINEMENT}

Refinement was done using the "FullProf" software (Rodriguez-Carjaval, 1997). Diffraction peaks were indexed based on lattice parameters derived from the Guinier powder photographs. Beginning with the phases where the crystal structure and approximate composition was known, each phase was refined separately to convergence by employing the following sequence of steps: (1) refinement of global parameters such as lattice parameters and peak profile parameters for the peak profile function identified suitable (Pseudo-Voigt), (2) atom position parameters, (3) occupation factors, peak assymmetry, and preferred orientation. The total number of parameters refined was 56 .

\section{RESULTS}

Three phases were present in the alloy investigated (Figure 1): A dominant phase indexed using a hexagonal unit cell $[a=0.43939(4) \mathrm{nm}, c=0.6012(5) \mathrm{nm}]$ and two minority phases, identified to be $\mathrm{Cu}_{10} \mathrm{Sn}_{3}$ (spacegroup $P 6_{3} / m$, Lenz and Schubert, 1971) and $\mathrm{CuSn}_{3} \mathrm{Ti}_{5}$ (Schuster et al., 1999), respectively. Reducing the symmetry of $\mathrm{Cu}_{10} \mathrm{Sn}_{3}$ to space group $\mathrm{P6}_{3}$ (Brandon et al., 1975) did not result in comparable $R_{\mathrm{Bragg}}$ factors unless the $\mathrm{Sn}$ content was allowed to decrease by about one-third of the starting value, which is unacceptable in view of the $\mathrm{Cu}-\mathrm{Sn}$ phase diagram.

Initial attempts to refine the majority phase in spacegroup $\mathrm{P}_{3} / m m c$ with $\mathrm{CaIn}_{2}$ structure type did not yield

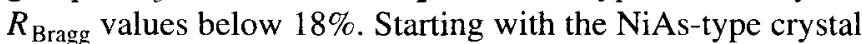
structure of $\mathrm{Cu}_{6} \mathrm{Sn}_{5}$ (Gangulee et al., 1973), however, opened the door to successfull refinement. Assuming the space group $P 6_{3} / m m c$, the atomic positions $(2 d)$ for $\mathrm{Cu}$, (2c) for $\mathrm{Sn}$, and $(2 a)$ for $\mathrm{Ti}$, and allowing for some mutal site exchange between $\mathrm{Cu}$ and $\mathrm{Ti}$, refinement to convergence resulted in a final $R_{\text {Bragg }}$ value of $5.60 \%$ (Table I). For the

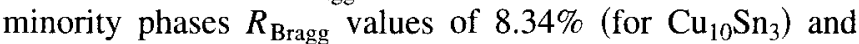
$10.30 \%$ (for $\mathrm{CuSn}_{3} \mathrm{Ti}_{5}$ ) were obtained. Thus the new ternary phase is labeled CuSnTi. This composition is corroborated by EPMA (Naka et al., 1999). It is isostructural to $\mathrm{InNi}_{2}$. In 


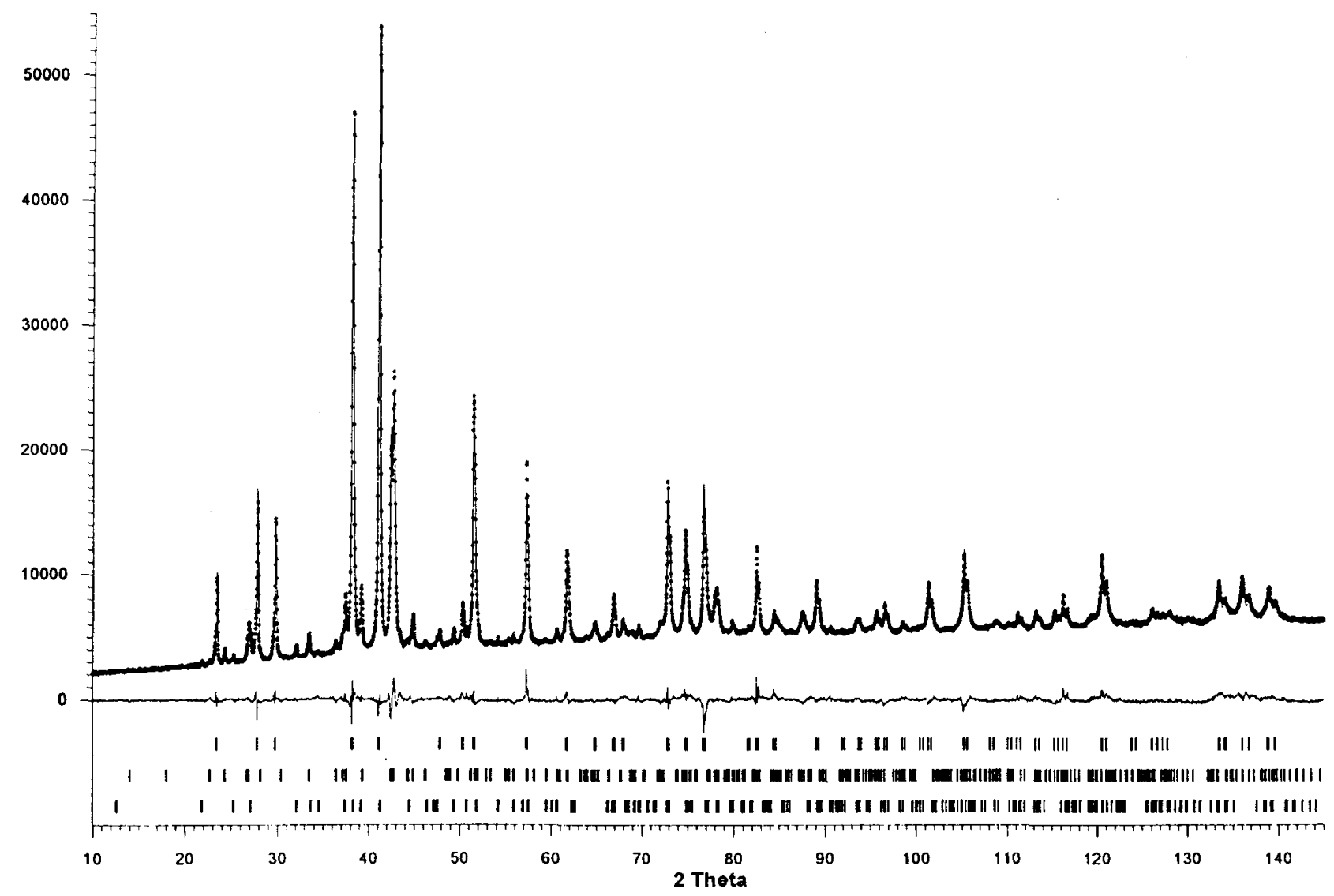

Figure 1. Diffraction profile of alloy $\mathrm{Cu}_{45} \mathrm{Sn}_{30} \mathrm{Ti}_{25}$ (arc melted and annealed at $\left.800{ }^{\circ} \mathrm{C}\right)$ using $\mathrm{CuK} \alpha$-radiation. Top: dots $=$ data points observed $\left(I_{\mathrm{obs}}\right)$; line $=$ calculated profile $\left(I_{\text {calc }}\right)$. Below: line $=$ difference $I_{\text {obs }}-I_{\text {calc }}$. Bottom: Bragg peak positions for $\mathrm{CuSnTi}$ (highest line), $\mathrm{Cu}_{10} \mathrm{Sn}_{3}(\mathrm{center}$ line), and $\mathrm{CuSn}_{3} \mathrm{Ti}_{5}$ (lowest line) calculated using the lattice parameters given in Table $\mathbf{I}$.

TABLE I. Crystallographic data obtained from refinement (final chi2 $=5.58$ ).

\begin{tabular}{cccccc}
\hline \hline & \multicolumn{4}{c}{$\begin{array}{c}\text { Space group: } P 6_{3} / m m c, h P 6, \mathrm{InNi}_{2} \text {-type, } \\
a=0.43955(5) \mathrm{nm}, c=0.601505(9) \mathrm{nm} ;\end{array}$} \\
Main phase: CuSnTi & $x$ & $y$ & $z$ & $B$ & occup. \\
& 104 reflections refined; $R_{\mathrm{Bragg}}=5.60 \%, R_{f}=4.11 \%$ & \\
$\mathrm{Cu}_{1}$ in $(2 d)$ & $1 / 3$ & $2 / 3$ & $3 / 4$ & 0.4 & 1.81 \\
$\mathrm{Ti}_{1}$ in $(2 d)$ & $1 / 3$ & $2 / 3$ & $3 / 4$ & 0.4 & $0.190(6)$ \\
$\mathrm{Sn}_{1}$ in $(2 c)$ & $1 / 3$ & $2 / 3$ & $1 / 4$ & 0.2 & 2.00 \\
$\mathrm{Cu}_{2}$ in $(2 a)$ & 0 & 0 & 0 & 0.4 & 0.16 \\
$\mathrm{Ti}_{2}$ in $(2 a)$ & 0 & 0 & 0 & 0.4 & $1.803(6)$
\end{tabular}

Space group: $P 6_{3} / m, h P 26, \mathrm{Cu}_{10} \mathrm{Sn}_{3}$-type $a=0.73314(2) \mathrm{nm}, c=0.78640(3) \mathrm{nm}$

Second phase: $\mathrm{Cu}_{10} \mathrm{Sn}_{3}$ 638 reflections refined; $R_{\mathrm{Bragg}}=8.34 \%, R_{f}=7.01 \%$

\begin{tabular}{|c|c|c|c|c|c|}
\hline & $x$ & $y$ & $z$ & $B$ & occup. \\
\hline $\mathrm{Cu}_{1}$ in $(12 i)$ & $0.6701(8)$ & $0.0239(8)$ & $0.0792(6)$ & 0.4 & 12.00 \\
\hline $\mathrm{Sn}_{1}$ in $(6 h)$ & $0.2958(7)$ & $0.9763(8)$ & $1 / 4$ & 0.2 & $4.74(6)$ \\
\hline $\mathrm{Ti}_{1}$ in $(6 h)$ & $0.2958(7)$ & $0.9763(8)$ & $1 / 4$ & 0.3 & 1.30 \\
\hline $\mathrm{Cu}_{2}$ in $(4 f)$ & $1 / 3$ & $2 / 3$ & $0.0709(12)$ & 0.4 & 4.00 \\
\hline $\mathrm{Cu}_{3}$ in $(2 d)$ & $2 / 3$ & $1 / 3$ & $1 / 4$ & 0.2 & 2.00 \\
\hline $\mathrm{Cu}_{4}$ in $(2 b)$ & 0 & 0 & 0 & 0.4 & 2.00 \\
\hline \multirow[t]{2}{*}{ Third phase: $\mathrm{CuSn}_{3} \mathrm{Ti}_{5}$} & \multicolumn{5}{|c|}{$\begin{array}{c}\text { Space group: } P 6_{3} / m c m, h P 18, \mathrm{Ti}_{5} \mathrm{Ga}_{4} \text {-type } \\
a=0.81507(7) \mathrm{nm}, c=0.55895(6) \mathrm{nm} \\
269 \text { reflections refined; } R_{\mathrm{Bragg}}=10.3 \% R_{f}=6.85 \%\end{array}$} \\
\hline & $x$ & $y$ & $z$ & $B$ & occup. \\
\hline $\mathrm{Sn}_{1}$ in $(6 g)$ & $0.6163(6)$ & 0 & $1 / 4$ & 0.2 & 6.00 \\
\hline $\mathrm{Ti}_{1}$ in $(6 \mathrm{~g})$ & $0.2720(16)$ & 0 & $1 / 4$ & 0.2 & 6.00 \\
\hline $\mathrm{Ti}_{2}$ in $(4 d)$ & $1 / 3$ & $2 / 3$ & 0 & 0.2 & 4.00 \\
\hline $\mathrm{Cu}_{1}$ in $(2 b)$ & 0 & 0 & 0 & 0.2 & $1.04(4)$ \\
\hline
\end{tabular}


TABLE II. Powder diffraction pattern of CuSnTi calculated from the parameters given in Table $\mathrm{I}$ for Guinier chamber geometry and $\mathrm{CuK} \alpha_{1}$ radiation ( $x$ marks the reflections observed on the Guinier film).

\begin{tabular}{rrlrrrl}
\hline \hline$h$ & $k$ & $l$ & $\begin{array}{c}d \text {-value } \\
\text { in } \AA\end{array}$ & $\sin ^{2} \vartheta$ & $\begin{array}{r}\text { Relative } \\
\text { intensity }\end{array}$ \\
\hline 1 & 0 & 0 & 3.8066 & 0.04095 & 143.1 & $x$ \\
1 & 0 & 1 & 3.2166 & 0.05735 & 207.9 & $x$ \\
0 & 0 & 2 & 3.0075 & 0.06560 & 267.5 & $x$ \\
1 & 0 & 2 & 2.3598 & 0.10654 & 897.2 & $x$ \\
1 & 1 & 0 & 2.1978 & 0.12284 & 1000.0 & $x$ \\
2 & 0 & 0 & 1.9033 & 0.16379 & 24.2 & $x$ \\
2 & 0 & 1 & 1.8146 & 0.18019 & 45.9 & $x$ \\
1 & 1 & 2 & 1.7745 & 0.18844 & 372.4 & $x$ \\
1 & 0 & 3 & 1.7740 & 0.18854 & 43.3 & $x$ \\
2 & 0 & 2 & 1.6083 & 0.22938 & 285.7 & $x$ \\
0 & 0 & 4 & 1.5037 & 0.26239 & 108.6 & $x$ \\
2 & 1 & 0 & 1.4388 & 0.28663 & 23.4 & \\
2 & 1 & 1 & 1.3993 & 0.30303 & 49.5 & $x$ \\
1 & 0 & 4 & 1.3986 & 0.30334 & 21.9 & $x$ \\
2 & 0 & 3 & 1.3804 & 0.31138 & 24.1 & $x$ \\
2 & 1 & 2 & 1.2979 & 0.35222 & 319.5 & $c$ Ge $(331)$ \\
3 & 0 & 0 & 1.2689 & 0.36852 & 212.9 & $x$ \\
3 & 0 & 1 & 1.2415 & 0.38492 & 0.0 & \\
1 & 1 & 4 & 1.2410 & 0.38523 & 408.5 & $x$ \\
2 & 0 & 4 & 1.1799 & 0.42618 & 16.5 & \\
3 & 0 & 2 & 1.1691 & 0.43412 & 140.9 & $x$ \\
2 & 1 & 3 & 1.1689 & 0.43422 & 39.5 & $x$ \\
1 & 0 & 5 & 1.1471 & 0.45093 & 19.8 & $x$ \\
2 & 2 & 0 & 1.0989 & 0.49136 & 185.1 & $x$ \\
3 & 0 & 3 & 1.0722 & 0.51611 & 0.0 & \\
3 & 1 & 0 & 1.0558 & 0.53231 & 17.5 & \\
3 & 1 & 1 & 1.0399 & 0.54871 & 46.4 & $x$ \\
2 & 1 & 4 & 1.0396 & 0.54902 & 36.3 & $x$ \\
2 & 2 & 2 & 1.0321 & 0.55696 & 156.3 & $x$ \\
\hline \hline
\end{tabular}

Table II the powder diffraction pattern calculated for CuSnTi using the parameters in Table $I$ is given. Powder diffractograms calculated from these data for $\mathrm{Cu}_{10} \mathrm{Sn}_{3}$ and $\mathrm{CuSn}_{3} \mathrm{Ti}_{5}$ match excellently the patterns published by Lenz and Schu- bert (1971) and Schuster et al. (1999), respectively.

It is interesting to note that other ternary $\mathrm{Cu}-\mathrm{Sn}-\mathrm{Me}$ alloys of 1:1:1 composition are reported to have $\mathrm{CaIn}_{2}$-type crystal structure for $\mathrm{Me}=\mathrm{Sc}, \mathrm{Y}$, and $\mathrm{RE}$ metal, but $\mathrm{InNi}_{2}$-type structure for $\mathrm{Me}=\mathrm{Dy}$ (Villars and Calvert, 1991). On the other hand, the phase CuSiTi crystallizes with $\mathrm{Co}_{2} \mathrm{Si}$-type structure (Villars and Calvert, 1991).

Due to the small amounts of the minority phases present in the sample investigated the accuracy of parameter determination as well as the reliability factors obtained for $\mathrm{Cu}_{10} \mathrm{Sn}_{3}$ and $\mathrm{CuSn}_{3} \mathrm{Ti}_{5}$ are considerably inferior than the data regarding CuSnTi (Table I). Nevertheless, the data clearly show that $\mathrm{Cu}_{10} \mathrm{Sn}_{3}$ crystallizes in spacegroup $P 6_{3} / m$ rather than $P 6_{3}$. Furthermore, $\mathrm{Cu}_{10} \mathrm{Sn}_{3}$ is found to dissolve (about 5 at $\%$ ) Ti on the $\mathrm{Sn}$ sites. The phase $\mathrm{CuSn}_{3} \mathrm{Ti}_{5}$ is found to be stoichiometric confirming the proposed structure (Schuster et al., 1999).

Brandon, J. K., Pearson, W. B., and Tozer, D. J. H. (1975). "A single crystal $\mathrm{x}$-ray study of the $\zeta$ bronze structure, $\mathrm{Cu}_{20} \mathrm{Sn}_{6}$," Acta Crystallogr., Sect. B: Struct. Crystallogr. Cryst. Chem. B31, 774-779.

Gangulee, A., Das, G. C., and Bever, M. B. (1973). "An x-ray diffraction and calorimetric investigation of the compound $\mathrm{Cu}_{6} \mathrm{Sn}_{5}$," Metal. Trans. 4, 2063-2066.

Lenz, J., and Schubert, K. (1971). "Crystal structure of $\mathrm{Cu}_{10} \mathrm{Sn}_{3}(\mathrm{~m})$," Monatsh. Chem. 102, 1689-1698.

Naka, M., Shibayanagi, T., and Schuster, J. C. (1999). "Phase equilibria in the system $\mathrm{Cu}-\mathrm{Sn}-\mathrm{Ti}$ '" (unpublished)

Rietveld, H. M. (1969). "A profile refinement method for nuclear and magnetic structures," J. Appl. Crystallogr. 2, 65-71.

Rodriguez-Carjaval, J. (1997). Computer program "FullProf," version 3.3, Aug. 97-LLB-JRC (Laboratoire Leon Brillouin, CEA-CNRS, Grenoble, France).

Schuster, J. C., Naka, M., and Shibayanagi, T. (1999). "Crystal structure of the phase $\mathrm{CuSn}_{3} \mathrm{Ti}_{5}$ '" (unpublished).

Urai, S., Kimura, H., Maeda, K., and Naka, M. (1998). "Brazing of SiC using CuSnTi alloys," DVS Ber. 192, 314-316.

Villars, P., and Calvert, L. D. (1991) Pearsons Handbook of Crystallographic Data for Intermetallic Phases (ASM, Materials Park, $\mathrm{OH}$ ). 